\title{
COMPARISON OF LUNG CANCER RISK IN BLACK-COAL MINERS BASED ON MORTALITY AND INCIDENCE
}

\author{
Hana Tomáškovái, ${ }^{1,2}$ Anna Šplíchalová ${ }^{2}$, Hana Šlachtová ${ }^{1,2}$, Zdeněk Jirák ${ }^{2,3}$ \\ ${ }^{1}$ University of Ostrava, Ostrava, Czech Republic \\ Faculty of Medicine, Centre for Epidemiological Research \\ ${ }^{2}$ Institute of Public Health in Ostrava, Ostrava, Czech Republic \\ ${ }^{3}$ University of Ostrava, Ostrava, Czech Republic \\ Faculty of Medicine, Department of Epidemiology and Public Health
}

\begin{abstract}
Background: Cancer risk (especially as regards lung cancer) in black-coal miners is mainly analyzed on the basis of mortality. The risk calculated based on mortality may differ from the values based on incidence. The aim of the study was to compare cancer risk in black-coal miners with and without coal workers' pneumoconiosis (CWP), based on data on mortality and the incidence of lung cancer in the Czech Republic in 1992-2013. Material and Methods: The cohort without CWP was composed of 6687 miners, and the cohort with CWP of 3476 miners. Information on the incidence of lung cancer was obtained from the Czech National Oncological Register (NOR), and information on mortality from the National Population Register. The risk of lung cancer incidence was compared with the general male population in the Czech Republic using the standardized incidence ratio (SIR), and the risk of lung cancer mortality using the standardized mortality ratio (SMR), with the 95\% CI. Results: In miners with CWP, a lower SMR value was found, SMR = 1.70 (95\% CI: 1.41-2.04), compared with the SIR value, SIR = 2.01 (95\% CI: $1.70-2.36$ ). In miners without CWP, this was opposite, the value of SIR $=0.81$ (95\% CI: $0.69-0.94)$ was lower than the value of SMR $=0.83$ (95\% CI: 0.70-0.98). In miners without CWP, 17 cases of lung cancer (out of 176 cases in total) were not registered in NOR. In miners with CWP, the share of not registered cases was significantly lower $(p=0.018)$, and it was represented by $3 \%$ of not registered lung cancer cases, out of 156 cases with the diagnosis of lung cancer. Conclusions: In spite of the difference between SIR and SMR, the results of both indicators were consistent with the resulting relationship between the lung cancer risk and CWP. Med Pr. 2020;71(5):513-8
\end{abstract}

Key words: lung cancer, aging, standardized mortality ratio, standardized incidence ratio, misleading results, coal workers' pneumoconiosis

Corresponding author: Hana Tomášková, University of Ostrava, Faculty of Medicine, Centre for Epidemiological Research, Syllabova 19, 70300 Ostrava, Czech Republic, e-mail: hana.tomaskova@osu.cz

Received: October 24, 2019, accepted: February 27, 2020

\section{INTRODUCTION}

In the 1950s, the city of Ostrava was called the "steel heart" of the Czech Republic. It was thanks to its status as a chemical, metallurgical and coal-mining industry centre, but since the Velvet Revolution (the fall of communism in 1989), its economic base has changed. In 1995-1999, about 20000 miners worked there, but over the years this number decreased to approximately 6500 active miners in 2018 .

The profession of black-coal miners is very hard and miners are exposed to a lot of risk factors (noise, vibrations transmitted to the hands, a high working and heat load, microclimatic conditions, psychological stress). The most important factor that is very dangerous to human health is dust containing the crystalline form of silica $\mathrm{SiO}_{2}$ that primarily causes coal workers' pneumoconiosis (J60 according to ICD-10 - CWP). In 1997, the International Agency for Research on Cancer (IARC) included blackcoal dust into group $1[1,2]$.

When assessing cancer risk (especially as regards lung cancer) in black-coal miners, a number of large studies [3-5] are based on mortality data. The risk calculated based on mortality may differ from the values based on incidence, and this risk is assumed to be un-

Funding: this study was supported by the Research Support Foundation, Vaduz. Markus R. Tödtli Consulting (grant entitled "Mortality in Miners with Coal-Workers' Pneumoconiosis in the Czech Republic," grant manager: Hana Tomaskova, Assoc. Prof.) and by the Operational Programme Research, Development and Education of the Ministry of Education, Youth and Sports of the Czech Republic (project No. CZ.02.1.01/0.0/0.0/16_019/0000798 entitled “Healthy Aging in Industrial Environment HAIE," project manager: Radim Sram, Ph.D.). 
derestimated. The underestimation of risk when using the standardized mortality ratio (SMR) was pointed out in the work by Möhner [6].

The presented analysis is based on data from an earlier study that was supported by a grant of the Research Support Foundation, Vaduz. Markus R. Tödtli Consulting. The aim of the current study is to compare the relationship between the estimated lung cancer risk correlated with aging in the occupationally exposed population in 1992-2013, using 2 approaches based on mortality and incidence. The cancer risk in miners was evaluated within the framework of longitudinal monitoring of coal miners in the Czech Republic, according to both the incidence of cancer [7], as well as total and specific mortality [8]. The analysis was performed with respect to the presence/absence of CWP.

\section{MATERIAL AND METHODS}

\section{Study design and data}

The first of the analyzed cohorts was composed of miners with CWP diagnosed in 1992-2013, in total 3476 miners. The other cohort consisted of miners without CWP who finished their work underground after achieving above $90 \%$ of the maximum permissible exposure [8] till $1999(\mathrm{~N}=6687)$. The information on lung cancer was obtained from the Czech National Oncological Register (NOR), and information on the cause of death from the National Population Register.

\section{Statistical analyses}

A descriptive analysis was used for the description of the sample. The risk of lung cancer (malignant neoplasm of bronchus and lung, i.e., C34 according to ICD10) and the incidence/mortality in miners were compared with the general male population in the Czech Republic using the standardized incidence ratio (SIR), SMR, and the $95 \% \mathrm{CI}$. The expected numbers of deaths and new lung cancer cases were calculated based on the male population in the Czech Republic. The data was analyzed by 5 -year age cohorts for the age ranging 30 to $\geq 95$. The data on the male population was obtained from the Institute for Health Information and Statistics of the Czech Republic. Data analyses were performed using the Stata software version 14 (StataCorp LP, College Station, TX, USA) [9].

\section{Ethical consideration}

The Ethics Committee of the Institute of Public Health in Ostrava, Czech Republic, approved the study (No. 1/2014).

\section{RESULTS}

\section{Description of the sample}

The cohort of miners with CWP was composed of 3476 men. The age of miners with CWP at the time of CWP diagnosis ranged 22-93 years. The average period from the diagnosis of the occupational disease till 2013 (or death) was 12.1 years. In the sample, CWP with the typical radiological signs predominated (70.9\%), including $17.4 \%$ of miners with CWP in relation to dynamic progression of the disease, $6.7 \%$ with complicated CWP, and 5\% with CWP connected with tuberculosis. The smoking anamnesis was available for $77.7 \%$ of persons, out of whom $44.8 \%$ were smokers, $33.4 \%$ non-smokers and $21.8 \%$ - ex-smokers (Table 1 ).

The cohort of miners without CWP consisted of 6687 men. The age of miners without CWP ranged 2962 years at the time of commencing the monitoring (termination of work in the mine). The average time since the cessation of work in the mine till 2013 (or death) was around 18.8 years. The smoking anamnesis was available for $99.8 \%$ of persons, out of whom $53.8 \%$ were smokers, $32.7 \%$ non-smokers and $13.5 \%$ ex-smokers at the time of termination of work in the mine (Table 1).

\section{Lung cancer}

Incidence

Based on the NOR data, 498 cases of cancer in total (excluding malignant neoplasm of the skin, i.e., C44 according to ICD-10) were identified in miners with CWP in 1992-2013, out of whom 151 (30\% of the reported cancer cases) had lung cancer (C34). The average age at the time of lung cancer diagnosis was 65.7 years (ranging 44-91 years). The average exposure duration was 24.6 years and this group was composed of $22 \%$ of non-smokers and $78 \%$ of smokers, including ex-smokers, but the information was not obtained for 33\% of miners with both CWP and diagnosed lung cancer. The calculated risk of lung cancer was significantly higher in miners with CWP ( $\mathrm{p}<0.001)$, SIR $=2.01$ (95\% CI: 1.70-2.36) compared with the general male population in the Czech Republic (Table 2, Figure 1).

In miners without CWP, 814 cases of cancer (excluding malignant neoplasm of skin, i.e., C44 according to ICD-10) were registered in NOR in 1992-2003, out of which 159 were lung cancer cases $(20 \%$ of the selected cancer cases). The average age at the time of registration in NOR for lung cancer was 61.5 years (ranging 3776 years). The average duration of exposure was 27 years. In this group, $9 \%$ of non-smokers and $91 \%$ of smok- 
Table 1. Description of the sample of miners with coal-workers' pneumoconiosis (CWP) (the Czech Republic, 1992-2013) and without CWP (the Ostrava-Karvina region, 1992-2013)

\begin{tabular}{|c|c|c|}
\hline \multirow{2}{*}{ Variable } & \multicolumn{2}{|c|}{$\begin{array}{c}\text { Miners } \\
(\mathrm{N}=10163)\end{array}$} \\
\hline & $\begin{array}{l}\text { with CWP } \\
(\mathrm{N}=3476)\end{array}$ & $\begin{array}{l}\text { without CWP } \\
(\mathrm{N}=6687)\end{array}$ \\
\hline $\begin{array}{l}\text { Age at the time of entering the study [years] } \\
(\mathrm{M} \pm \mathrm{SD})\end{array}$ & $49.7 \pm 12.4$ & $44.0 \pm 6.3$ \\
\hline Duration of exposure $^{\mathrm{a}}$ [years] $(\mathrm{M} \pm \mathrm{SD})$ & $20.7 \pm 7.8$ & $22.9 \pm 5.9$ \\
\hline \multicolumn{3}{|l|}{ Smoking status ${ }^{\mathrm{b}}[\%]$} \\
\hline smoker & 54 & 45 \\
\hline ex-smoker & 14 & 22 \\
\hline \multicolumn{3}{|l|}{ Lung cancer } \\
\hline incidence [n (\%)] & $151(4.3)$ & $159(2.4)$ \\
\hline age at the time of diagnosis [years] $(\mathrm{M} \pm \mathrm{SD})$ & $65.7 \pm 9.4$ & $61.5 \pm 7.3$ \\
\hline duration of exposure [years] $(\mathrm{M} \pm \mathrm{SD})$ & $24.6 \pm 8.8$ & $27.0 \pm 5.2$ \\
\hline \multicolumn{3}{|l|}{ smoking status ${ }^{\mathrm{b}}[\%]$} \\
\hline smoker & 55 & 79 \\
\hline ex-smoker & 23 & 12 \\
\hline mortality [n (\%)] & $116(3.3)$ & $143(2.1)$ \\
\hline age at the time of death [years] $(\mathrm{M} \pm \mathrm{SD})$ & $66.3 \pm 9.6$ & $61.9 \pm 7.5$ \\
\hline duration of exposure $^{\mathrm{a}}$ [years] $(\mathrm{M} \pm \mathrm{SD})$ & $24.6 \pm 8.7$ & $26.7 \pm 5.6$ \\
\hline \multicolumn{3}{|l|}{ smoking status ${ }^{\mathrm{b}}[\%]$} \\
\hline smoker & 55 & 79 \\
\hline ex-smoker & 20 & 12 \\
\hline
\end{tabular}

${ }^{a}$ In the sample of miners with CWP, information on exposure was missing in $6 \%$ of the whole sample, in $11 \%$ of persons with C34, and in $15 \%$ of persons who died from C34; in miners without CWP, information was available for all persons.

${ }^{b}$ In the sample of miners with CWP, information on the smoking status was missing in $22 \%$ of the whole sample, in $33 \%$ of persons with C 34 and in $25 \%$ of persons who died from C34; in miners without CWP, missing information was found in 12 persons $(0.18 \%)$, in persons with C34 and in persons who died from C34 information on the smoking status was available for all persons.

ers, including ex-smokers, were detected. The information on exposure as well as on the smoking status was obtained for nearly all persons. The risk of lung cancer was significantly lower $(\mathrm{p}<0.001), \mathrm{SIR}=0.81(95 \% \mathrm{CI}$ : 0.69-0.94) compared with the general male population in the Czech Republic (Table 2, Figure 1).

\section{Mortality}

Out of 889 deaths in miners with CWP registered in the study period (1992-2013), 116 (13.0\%) were caused by lung cancer (Table 1). The risk of death from lung cancer was significantly higher $(\mathrm{p}<0.001), \mathrm{SMR}=1.70$ (95\% CI: 1.41-2.04) compared with the general male population in the Czech Republic (Table 2, Figure 1).
Table 2. Comparison of lung cancer risk based on incidence and mortality with the general male population in the Czech Republic in 1992-2013

\begin{tabular}{|c|c|c|}
\hline \multirow{2}{*}{ Health indicators } & \multicolumn{2}{|c|}{$\begin{array}{l}\text { Miners diagnosed with C34 } \\
\qquad(\mathrm{N}=332)\end{array}$} \\
\hline & $\begin{array}{l}\text { with CWP } \\
(\mathrm{N}=156)\end{array}$ & $\begin{array}{l}\text { without CWP } \\
\qquad(\mathrm{N}=176)\end{array}$ \\
\hline Cases - C34 diagnosis in NOR [n (\%)] & $151(97)$ & $159(90)$ \\
\hline Expected numbers $^{\mathrm{a}}[\mathrm{n}]$ & 75.1 & 196.5 \\
\hline $\operatorname{SIR}(95 \% \mathrm{CI})$ & $2.01(1.70-2.36)$ & $0.81(0.69-0.94)$ \\
\hline \multicolumn{3}{|l|}{ Death $[\mathrm{n}(\%)]$} \\
\hline no (C34 diagnosis in NOR) & $40(26)$ & $33(19)$ \\
\hline yes (C34 diagnosis in NOR) & $111(71)$ & $126(72)$ \\
\hline $\begin{array}{l}\text { total (C34 diagnosis in the National } \\
\text { Population Register) }\end{array}$ & $116(74)$ & $143(81)$ \\
\hline expected numbers $^{\mathrm{a}}[\mathrm{n}]$ & 68.1 & 171.4 \\
\hline $\operatorname{SMR}(95 \% \mathrm{CI})^{\mathrm{b}}$ & $1.7(1.41-2.04)$ & $0.83(0.70-0.98)$ \\
\hline \multicolumn{3}{|l|}{ NOR $[\mathrm{n}(\%)]$} \\
\hline C34 diagnosis & $111(71)$ & $126(72)$ \\
\hline other diagnoses & $5(3)$ & $8(5)$ \\
\hline not registered & $0(0)$ & $9(5)$ \\
\hline
\end{tabular}

CWP - coal-workers' pneumoconiosis, C34 diagnosis - "malignant neoplasm of bronchus and lung" according to the International Classification of Diseases (ICD-10), NOR - National Oncological Register.

SIR - standardized incidence ratio, SMR - standardized mortality ratio.

a Expected numbers of deaths and new cases of lung cancer were calculated based on the male population in the Czech Republic.

${ }^{\mathrm{b}}$ Results published in Tomášková et al. [8].

In total, 1320 miners from the cohort without CWP $(\mathrm{N}=6687)$ died in the study period. Among these, lung cancer (C34) was listed as the cause of death in 143 $(10.8 \%)$ miners (Table 1$)$. The risk of death from lung cancer was significantly lower $(\mathrm{p}<0.001), \mathrm{SMR}=0.83$ (95\% CI: 0.70-0.98) compared with the general population (Table 2, Figure 1).

\section{Comparison of deaths and cases registered in NOR with malignant neoplasm of bronchus and lung (C34)} Based on a detailed analysis, some discrepancy was found in the total number of diagnosed C34 cases (Table 2). The total number of lung cancer cases in miners with CWP was 156 (based on NOR and the National Population Register), and in miners without CWP it was 176 . In miners with CWP, 5 cases (3\%) were listed with C34 as the cause of death, but in NOR these persons were registered for other or earlier oncological diagnoses (in 2 cases, it was $\mathrm{C} 80$, and in the remaining 5 C32, C38 and C43). The difference between the NOR evidence and death was 2 months in 2 cases; in other 


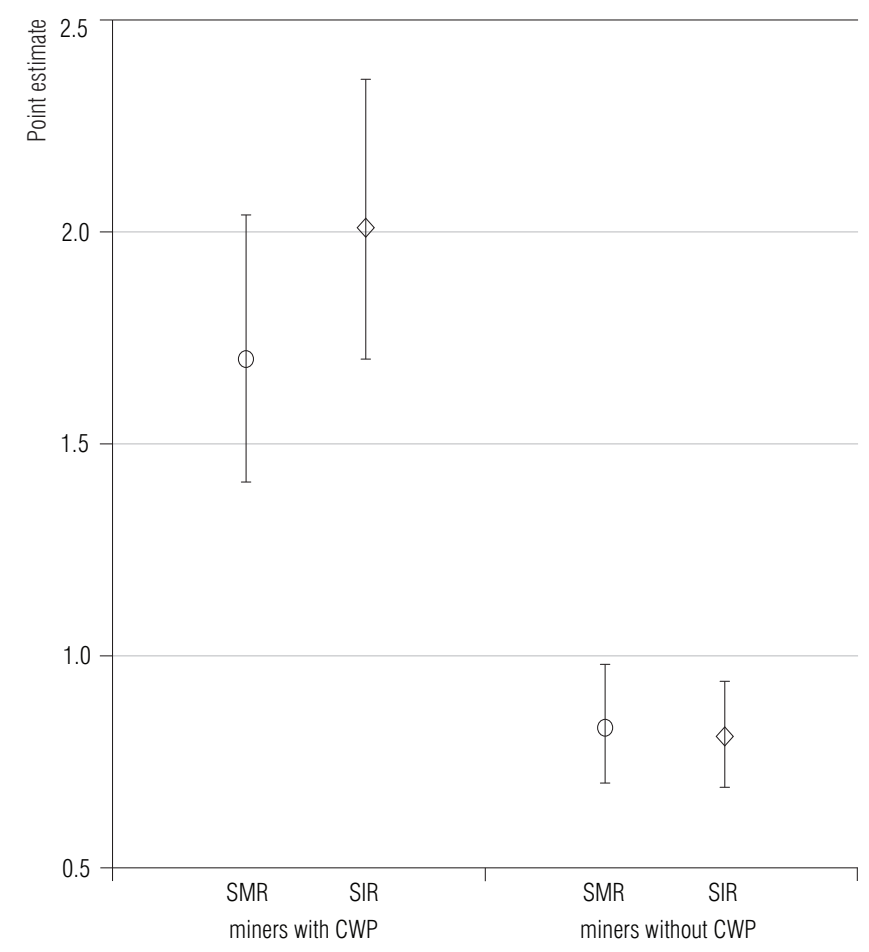

Figure 1. Lung cancer risk expressed by the calculated standardized mortality ratio (SMR) and the standardized incidence ratio (SIR) in miners with and without coal-workers' pneumoconiosis (CWP)

2 cases, the difference was $\leq 2$ years, and in 1 case it was 6 years.

In miners without CWP, differences between the study and NOR data regarding the causes of death were also found. Namely, 17 (10\%) lung cancer deaths in the cohort were registered in NOR with another or earlier oncological diagnosis than lung cancer, in addition to 9 cases which were not registered in NOR (dating back in 1992).

The number of lung cancer cases not registered in NOR was significantly higher in miners without CWP than in miners with CWP (Fischer's exact test, $\mathrm{p}=0.018$ ).

\section{DISCUSSION}

In the Czech Republic, at the end of the 20th century $>20000$ men worked in the black-coal miner profession. Much attention was paid to preventive occupational measures, and numerous experts dealt with cancer risk assessment in coal miners [10].

In 2005, the analysis of cancer risk was performed in coal miners being transferred from work underground, within the framework of a grant project that found a statistically insignificant increased risk of lung cancer in miners with CWP [11]. The analysis of this risk was based on the incidence of malignant cancer diseases. Based on this study, the cohort of miners without CWP was created and cancer risk in coal miners was analyzed in relation to CWP $[7,8]$.

The source of data was the National Register of Occupational Diseases that was established in 1992. Many large studies $[4,5]$ analyzed mortality, including lung cancer mortality in black-coal miners. These studies followed up cohorts mostly without employing a division of miners into those with and without CWP, which might contribute to the variability of results.

Furthermore, misleading results might be ascribed to determining the disease-specific risk based on mortality instead of incidence, as was pointed out by Möhner [6] The risk might be underestimated due to recording a different cause of death than the analyzed disease.

For this reason, many other authors analyzed the relationship between the listed cause of death and the actual health status [12]. In the studies included in this analysis, many inaccuracies in determining the cause of deaths were found.

For example, in a study conducted in Sri Lanka, the cause of death in cancer cases was determined correctly only in $62.5 \%$ [12]. In a Swedish study, the authors found that the reliability of the cause of death determination for cancer cases was correct in $92 \%$, while in benign tumors the correct determination was found only in $20 \%$ [13].

In the Czech Republic (Czechoslovakia till 1992), cancer incidence has been traced since 1976, which enables the analysis of cancer risk based on incidence [14]. The analysis based on incidence should provide more correct information about the exact cancer risk than the analysis based on mortality.

However, inaccuracies in the oncological register exist mostly due to some cases being left unreported in NOR [15]. These inaccuracies have continuously been eliminated, but some percentage of missing data is still found.

In this study, up to 22 lung cancer deaths (6.4\% out of all 332 lung cancer cases) were not recorded in NOR. In the cohort of miners with CWP, all 5 cases $(3 \%$ out of 156 lung cancer cases) might be the matter of not reported cases, where the persons were registered in NOR for another diagnosis. In the cohort of miners without CWP, the number is higher, and it is represented by 17 cases (10\% out of 176 lung cancer cases). Out of these, 8 cases had already been registered in NOR for another diagnosis, while 9 cases were not registered in NOR at all. 
In this cohort, the opposite effect was found, as the risk based on mortality was higher in this case than the assessment based on incidence. It is questionable whether an error had appeared in the statement of the cause of death that eventually led to the overestimation of cancer risk.

In the Czech Republic, under Act No. 372/2011 Coll. and its amendments, Act No. 147/2016 Coll. [16], the physician examining the body of the deceased may determine whether a pathological-anatomical or medical autopsy should be performed. The physician performing the examination might be a practitioner, a physician performing medical emergency or a physician in a medical facility where the person died, or a physician of a rescue health facility.

In case an autopsy is not ordered (the above law precisely determines the conditions to be fulfilled), the cause of death may be distorted in relation to the physician's knowledge of personal anamnesis of the deceased person. Also, a lack of trained physicians examining the body of the deceased may lead to an inaccurate determination of the cause of death [17]. The autopsy was provided in about $12 \%$ of deceased persons in 2015 , out of whom $70 \%$ died of natural causes [18].

\section{CONCLUSIONS}

A comparison of lung cancer risk in black-coal miners based on incidence and mortality confirmed the assumption that the lung cancer risk calculated on the basis of mortality (SMR) is underestimated in comparison with the calculation based on incidence (SIR). However, this assumption was confirmed only in miners with CWP, and the difference was not statistically significant.

Both indicators confirmed a significantly higher lung cancer risk in miners with CWP compared with the general male population in the Czech Republic (SIR = 2.01 , SMR = 1.70). Conversely, in miners without CWP, a slightly higher level of lung cancer risk based on SMR, compared with the level of SIR, was found (SMR $=0.83$ vs. SIR $=0.81$ ), but also in this case the difference between these 2 indicators was not statistically significant.

The risk of lung cancer in miners without CWP was significantly lower based on both indicators, compared with the general male population in the Czech Republic. Out of all 332 lung cancer cases, no record was found in NOR in 22 lung cancer deaths (6.4\%). A significantly higher number of cases not registered in NOR was detected in miners without CWP.
The analysis was performed to better understand the impact of occupational exposure on the health status of the newly established cohort of the middle-aged population (35-65 years) in the Healthy Aging in the Industrial Environment project [19] in the Ostrava-Karvina Region. With regard to the significant role of mining in this region, it is important to reflect the occupational anamnesis of the cohort participants, pay attention to the impact of the occupational exposure on their health, and take into account the possible shifts that may occur with this exposure.

\section{ACKNOWLEDGEMENTS}

The authors would like to thank the National Register of Occupational Diseases, the National Population Register and the National Oncological Register for providing the data.

\section{REFERENCES}

1. Monographs on the evaluation of carcinogenic risks to humans. Silica, some silicates, coal dust and para-aramid fibrils. Vol. 68. Lyon: IARC; 1997.

2. Straif K, Benbrahim-Tallaa L, Baan R, Grosse Y, Secretan B, El Ghissassi F, et al. WHO International Agency for Research on Cancer Monograph Working Group. A review of human carcinogens - part C: metals, arsenic, dusts, and fibres. Lancet Oncol. 2009;10(5):453-4.

3. Attfield MD, Kuempel ED. Mortality among U.S. underground coal miners: A 23-year follow-up. Am J Ind Med. 2008;51:231-45, https://doi.org/10.1002/ajim.20810.

4. Miller BG, Maccalman L. Cause-specific mortality in British coal workers and exposure to respirable dust and quartz. Occup Environ Med. 2010;67:270-6, https://doi.org/10.11 36/oem.2009.046151.

5. Graber JM, Stayner LT, Cohen RA, Conroy LM, Attfield MD. Respiratory disease mortality among US coal miners; results after 37 years of follow-up. Occup Envi-ron Med. 2014;71: 30-9, https://doi.org/10.1136/oemed-2013-101597.

6. Möhner M. An approach to adjust standardized mortality ratios for competing cause of death in cohort studies. Int Arch Occup Environ Health. 2016;89(4):593-8, https://doi. org/10.1007/s00420-015-1097-Z.

7. Tomaskova H, Jirak Z, Splichalova A, Urban P. Cancer incidence in Czech black coal miners in association with coalworkers' pneumoconiosis. Int J Occup Med Environ Health 2012;25(2):137-44, https://doi.org/10.2478/S13382012-0015-9.

8. Tomášková H, Šplíchalová A, Šlachtová H, Urban P, Hajduková Z, Landecká I, et al. Mortality in Miners with Coal- 
Workers' Pneumoconiosis in the Czech Republic in the Period 1992-2013. Int J Environ Res Public Health. 2017; 14:269, https://doi.org/10.3390/ijerph14030269.

9. Stata Statistical Software: Release 14.0. College Station, TX: Stata Corporation; 2015.

10. Kohout J. [Malignant Tumours in Miners with Pneumoconiosis]. Occup Med. 1989;41:351-3. Czech.

11. Tomaskova H, Jirak Z, Menzlova M, Beska F, Zavadilova V, Cimova $\mathrm{K}$, et al. [Prevalence of cancer diseases and evaluation of cancer risk in coal miners - an epidemiological study]. Occup Med. 2005;6(4):198-202. Czech.

12. Rampatige R, Gamage S, Peiris S, Lopez AD. Assessing the reliability of causes of death reported by the Vital Registration System in Sri Lanka: medical records review in Colombo. HIM J. 2013;42(3):20-8.

13. Johansson LA, Björkenstam C, Westerling R. Unexplained differences between hospital and mortality data indicated mistakes in death certification: an investigation of 1,094 deaths in Sweden during 1995. J Clin Epidemiol. 2009;62 (11):1202-9, https//:doi.org/10.1016/j.jclinepi.2009.01.010.

14. Siroky P, Novak J, Marsik V. [The development of the cancer registration system in the Czech Republic]. Klin Onkol. 1996;9(5):160-1. Czech.
15. Rousarova M, Podobsky J, Muzik J. [Ensuring the quality of the NOR data from the perspective of the regional workplace. Proceedings. XLI. Brno Oncology Days, XXXI. Conference for Non-medical Healthcare Professionals Laboratory Diagnostics in Oncology 2017]. Klin Onkol. 2017;30(Suppl 1):S31. Czech.

16. [Act No. 147/2016 Coll., that changed the Act No. 372/2011 Coll., about health services and conditions of their provision (Health Services Act), and its amendments]. Czech.

17. Rampatige R, Mikkelsen L, Hernandez B, Riley I, Lopez AD. Systematic review of statistics on causes of deaths in hospitals: strengthening the evidence for policy-makers. Bull World Health Organ. 2014;92(11):807-16, https:/doi.org/ 10.2471/BLT.14.137935.

18. Nechanska B, Vorel F. [Autopsies and toxicological examinations carried out by forensic medicine departments]. Praha: Institute of Health Informatics and Statistics in the CR; 2017. Czech.

19. Šlachtová H, Skýbová D, Dalecká A, Jandačková V, Tomášková $\mathrm{H}$, Jiřík $\mathrm{V}$, et al. [Healhy aging in the industrial environment - launch of the Research project]. Hygiena. 2019;64(1):31-4, https://doi.org/10.21101/hygiena.a1649. Czech.

This work is available in Open Access model and licensed under a Creative Commons Attribution-NonCommercial 3.0 Poland License - http://creativecommons.org/licenses/by-nc/3.0/pl/deed.en. 